\title{
Arquitectura para un carisma: carmelitas descalzos y tracistas de la Orden en España ${ }^{\top}$ Architecture for a Charism: Discalced Carmelites and Designers of the Order in Spain
}

\section{María Josefa Tarifa Castilla}

Universidad de Zaragoza

ESPAÑA

mjtarifa@unizar.es

[Hipogrifo, (issn: 2328-1308), 4.2, 2016, pp. 67-87]

Recibido: 04-01-2016/ Aceptado: 09-03-2016

DOI: http://dx.doi.org/10.13035/H.2016.04.02.07

Resumen. La arquitectura conventual del Carmelo Teresiano desarrollada a lo largo de los siglos de la Edad Moderna (XVI-XVIII) fue diseñada por los propios frailes tracistas de la Orden, como fray Alberto de la Madre de Dios (1575-1635) o fray Alonso de San José (1600-1654), con modelos arquitectónicos supeditados al carisma, reglamentos y finalidad de la misma y bajo unos postulados de pobreza, austeridad, funcionalidad y economía de medios. Conventos que se insertaron en la trama urbana existente en las ciudades, llegando en algunos casos a modificarla, como ejemplifica el complejo de carmelitas descalzos de Pamplona (1640-1672). Edificios en los que a través de la distribución de los espacios que los configuran se hace palpable el nuevo estilo de vida teresiano, como reflejan los planos dibujados en 1767 por fray José de San Juan de la Cruz para el convento navarro de religiosas de Lesaca.

Palabras clave. Arquitectura conventual, carmelitas descalzos, frailes tracistas, fray José de San Juan de la Cruz, España, Edad Moderna.

Abstract. The convent architecture of the Teresian Carmel developed over the centuries of the Early Modern Time (XVI-XVIII) was designed by friars of the Order, as brother Alberto de la Madre de Dios (1575-1635) or brother Alonso de San José

1. El presente estudio ha sido realizado en el marco del Proyecto I+D «Los diseños de arquitectura en la Península Ibérica entre los siglos XV y XVI. Inventario y Catalogación» (HAR2014-54281-P). 
(1600-1654). They used architectural models following the Carmelite charisma, regulations and purpose of the Order and under the assumptions of poverty, austerity, functionality and economy of means. Convents that were inserted into the existing urban planning of cities, and in some cases they even modified it, as the Discalced Carmelites complex of Pamplona (1640-1672) exemplifies. Buildings that through the distribution of space show the new style of life of Teresa, as the designs drawn in 1767 by brother José de San Juan de la Cruz for the Navarre nunnery of Lesaca reflect.

Keywords. Convent Architecture, Discalced Carmelites, Designer Friars, Brother José de San Juan de la Cruz, Spain, Early Modern Time.

\section{ARQUITECTURA PARA EL CARISMA DEL CARMELO TERESIANO}

En la primera mitad del siglo XVII la Orden del Carmen Descalzo asumió un papel relevante en la España de la Contrarreforma, tanto en su aspecto esencial, el religioso, con la defensa y difusión de la doctrina de Trento², como en el artístico, ya que su amplia propagación motivó la construcción de numerosos conventos a ella destinados en las ciudades. Esta realidad, común al resto de las órdenes, especialmente las nuevas o reformadas (capuchinos en 1578, agustinos descalzos en 1588, clérigos menores en 1594...) ha llevado a considerar al Barroco como un período determinante para el desarrollo de la cultura conventual en el interior de los núcleos urbanos ${ }^{3}$, desplazamiento que en el caso de las órdenes femeninas tuvo su origen en razones de seguridad, de acuerdo con las decisiones adoptadas por el Concilio de Trento 4 .

La renovación teresiana que inició su andadura entrada la segunda mitad del siglo XVI con un ritmo fundacional fulgurante, impulsado por la Santa, provocó que los conventos del Carmelo Descalzo se multiplicasen sin descanso desde 1562, con la apertura del primero dedicado a san José en Ávila ${ }^{5}$. Edificios que muestran entre ellos una similitud estilística, que a su vez está en sintonía con el panorama general de la arquitectura barroca de comienzos del seiscientos, de un lenguaje clasicista en el que impera la sobriedad de líneas. Uniformidad que responde, más que a la existencia de una exclusiva arquitectura carmelitana, a una propuesta arquitectónica que se repite de manera invariable en las distintas construcciones que estos religiosos erigieron de acuerdo a los planos diseñados por los frailes tracistas de la propia Orden. Conventos erigidos conforme a las necesidades y carisma teresiano, basado en los postulados de funcionalidad, sencillez, severidad, economía de líneas y elementos arquitectónicos.

2. Jedin, 1972, p. 772 .

3. Cámara Muñoz, 1990, pp. 103-153; Sebastián, 1997, p. 8; Atienza López, 2008. Para el caso de Navarra, ver Azanza López, 1998b, pp. 579-613.

4. López de Ayala, 1857, pp. 372-373.

5. Santa Teresa de Jesús, Libro de las Fundaciones; Escribano Hernández, 1987, pp. 201-230; Pérez, 2007, pp. 61-124; Muñoz Jiménez, 1989a, pp. 127-157. 
Un espíritu sobrio que quedó plasmado tanto en los escritos de santa Teresa de Jesús y san Juan de la Cruz, como en las normas emanadas de los Capítulos Generales de la Orden ${ }^{6}$. La santa recomendaba que los conventos tendrían la mayor simplicidad, pequeñez, austeridad y consistencia, insistiendo en el Camino de Perfección (cap. 2, núm. 9) que la casa carmelitana ha de ser «pobre y sobre todo chica» ${ }^{7}$. De igual modo, en las propias Constituciones que la fundadora redacta para sus monjas del Carmelo Descalzo (Salamanca, 1581) ${ }^{8}$, exige que «la casa jamás se labre, si no fuere la iglesia, ni haya cosa curiosa, sino tosca la madera; y sea la casa pequeña y las piezas bajas; casa que cumple a la necesidad y no superflua; fuerte lo más que pudieren y la cerca alta» (cap. 6, núm. 17) ${ }^{9}$. Directrices que se aplicaron al pie de la letra en la primera fundación que realizó santa Teresa en el convento de San José de Ávila en 1562, en la que impuso la pobreza absoluta en el modo de vida de una pequeña comunidad formada por un número reducido de religiosas, todas con el mismo tratamiento y rango, que transitaban en silencio por la casa, como refiere en el Libro de la Vida (cap. 32, núm. 9) ${ }^{10}$.

De igual forma se expresan las disposiciones de los Capítulos Generales de la Orden de Alcalá de Henares de 1581 y de Pastrana de 1604. A ello se sumó el esfuerzo por homogeneizar la arquitectura carmelitana, por lo que desde el generalato del Padre fray Elías de San Martín en 1594 se publicó un precepto dirigido a los priores para que no sobrepasasen las medidas constructivas establecidas, y para ello envió al tracista fray Francisco de Jesús a recorrer los conventos en construcción para imponer el rigor de las mismas. Un proceso que culminó con el siguiente general, el Padre fray Francisco de la Madre de Dios, que en 1600 reunió en Madrid a los frailes entendidos en arquitectura para que hicieran una traza moderada de convento, unificando criterios constructivos que afectasen a todos los conventos carmelitanos, ordenando diseñar unos planos generales que fuesen aplicados a los nuevos complejos carmelitas, como la iglesia de San Hermenegildo de Madrid - casa central de la congregación hispana-, imponiéndose desde 1605 dicho modelo como se documenta en las nuevas iglesias de Toro y Toledo, San Clemente, Peñaranda de Duero, Alcalá, Burgos y Yepes ${ }^{11}$.

En 1623 se imprimieron en Uclés la Regla Primitiva y Constituciones de la Orden, que básicamente reúnen las normas emanadas del Capítulo General de 1604, en cuyo capítulo primero de la segunda parte se enumeran las características de un convento carmelitano recogiendo sus medidas ${ }^{12}$. De la misma manera se expresan

6. San José, 1948, pp. 117-122; Muñoz Jiménez, 1990a, pp. 26-33; Narváez, 2015, pp. 176-189.

7. Santa Teresa de Jesús, Obras completas, pp. 189-190.

8. Fernández de Mendiola, 2008, p. 614.

9. Santa Teresa de Jesús, Obras completas, p. 617

10. Santa Teresa de Jesús, Obras completas, p. 133. Sobre la nueva ideología reformadora que quiere imponer Santa Teresa en el convento de la Encarnación, ver Steggink, 1965, pp. 357-380.

11. Silverio de Santa Teresa, 1937, pp. 702-703; Muñoz Jiménez, 1990a, pp. 26-30.

12. «Y porque no combiene a hombres, que están en este mundo, como peregrinos, y que professan pobreza, tener casas sumptuosas, ni curiosamente adornadas: ordenamos, que nuestros monasterios, nuestros templos no sean magníficos [...]. Y guardada esta proporción se disponga lo interior de la casa a juicio de los artífices». Citado en Fernández Gracia y Echeverría Goñi, 1981, pp. 789-790. Esta misma 
las Constituciones de las Religiosas Descalzas (cap., 12, núm., 5): «No se fabricarán con primores de Arquitectura los Conventos de nuestras Religiosas á excepcion de la Iglesia, edificándose conforme á las plantas que hicieren los Arquitectos de nuestra Orden, y no de otra manera. En los edificios se atenderá á la necesidad, y se excusará la superfluidad. Las paredes se harán lo más fuertes que fueren posible, y la cerca deberá ser tal alta» ${ }^{13}$.

En definitiva, textos en los que no hay una referencia a estilos, ni a peculiaridades de distribución del espacio en los complejos conventuales, sino que todo se concreta en pobreza de materiales, simplicidad en el diseño, austeridad ornamental y dimensiones moderadas.

\section{LA LABOR DE LOS FRAILES TRACISTAS DE LA ORDEN}

La mayor parte de los numerosos conventos construidos por los carmelitas descalzos a lo largo de los siglos XVI-XVIII fueron diseñados por los propios religiosos de la Orden ${ }^{14}$, cuya nómina aumenta progresivamente según se van realizando nuevos estudios referentes al tema ${ }^{15}$. Frailes tracistas que formados en el lenguaje clasicista imperante a comienzos del siglo XVII, desempeñaron un papel rector en la difusión de las formas barrocas, destacando la sobriedad de líneas en sus diseños. Maestros que en sus informes manejaron con autoridad la teoría artística (Vitruvio, Alberti, Serlio, Vignola, Palladio, Caramuel, Tosca, fray Lorenzo de San Nicolás) ${ }^{16}$, buena prueba de su capacidad al tener a su disposición las ricas bibliotecas conventuales, proporcionando una impronta muy personal a las edificaciones conventuales y no conventuales, pues, como es sabido, su actividad rebasó en gran medida el mundo del claustro, dada la fama que alcanzaron y su grado de especialización. Por ello, en el ejercicio de su profesión también fueron reclamados por instituciones ajenas a la Orden, dada su valía y buen hacer, como la realeza, la nobleza, los cabildos eclesiásticos, parroquias o ayuntamientos, para trazar, dirigir y tasar edificios, dejando ver en este caso su lado más creativo y exuberante, destacando además su movilidad en el desempeño de su oficio por los distintos territorios peninsulares o provincias carmelitanas en las que residieron y a las que fueron llamados, como ejemplificaremos posteriormente.

Al desempeño de su trabajo en el ámbito arquitectónico, también sumaron en algún caso el diseño de retablos, el dorado de los mismos y las habilidades de pintor y escultor, lo que nos permite apreciar la admirable versatilidad de la que hacían gala, hasta el punto de convertirse en consejeros y asesores artísticos. En

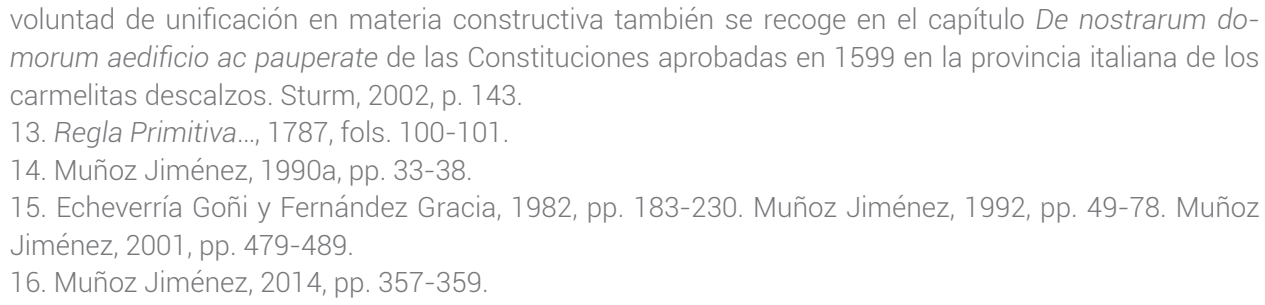


definitiva, estos frailes artistas desarrollaron cometidos técnicos similares a los que contemporáneamente desempeñaban arquitectos, ingenieros y delineantes, siendo patente su influencia en los diferentes campos artísticos a lo largo de los siglos del barroco.

De acuerdo con las Constituciones de los Descalzos de 1604, cuando la Orden estaba en plena expansión, la mayor parte de estos frailes tracistas fueron hermanos legos ${ }^{17}$, religiosos no clérigos, lo que no impidió que algunos frailes ordenados, e incluso priores, desempeñasen este cargo, como ejemplifican los conocidos nombres de fray Alonso de San José o fray Juan de San José. Frailes que, o bien eran maestros de obras seglares que ingresaban como legos en la Orden, o religiosos que se formaban en el seno del carmelo descalzo junto con otros frailes artífices peritos en la materia o a través del manejo de libros de arquitectura ${ }^{18}$.

Ellos tenían la importante labor de trazar los planos de acuerdo a los que se ejecutaban los edificios del Carmelo Teresiano, diseños arquitectónicos que debían respetarse en todos sus detalles por los maestros de obras que contratasen la fábrica de los mismos ${ }^{19}$. Construcciones que responden a cuatro tipologías principales, conventos masculinos, conventos femeninos, hospicios y también desiertos $^{20}$, que eran establecimientos eremíticos en los que desarrollar la vida contemplativa y la oración en común, junto a la meditación y prácticas devocionales en soledad, diseñados con una iglesia de una nave con crucero, dispuesta en medio de un rectángulo exterior formado por celdas dotadas de jardines, como el de San José de la Isla en Sestao (Vizcaya) que trazó fray Marcos de Santa Teresa (1719$1729)^{21}$.

El prototipo de convento carmelitano cristalizó en las trazas salidas de las manos de fray Alberto de la Madre de Dios (1575-1635) ${ }^{22}$, formado en el seno de la Orden y en el proceso de unificación de modelos arquitectónicos dirigida por el general fray Francisco de la Madre de Dios ${ }^{23}$. Planos en los que se imponen la sencillez, la austeridad y la uniformidad arquitectónica, de acuerdo con el clasicismo

17. Según estas disposiciones, «los que se reciben para el estado de legos, han de ser artífices, y no de cualquier arte sino de aquellas que pueden servir en la Orden, como la de ensamblador, entallador, escultor, carpintero, albañil, dorador, pintor, cirujano y que estén en dichas artes diestros y no sean principiantes». Citado en Echeverría Goñi y Fernández Gracia, 1982, p. 187.

18. Muñoz Jiménez, 2014, pp. 341-361.

19. El mismo texto de las Constituciones de 1604 ordenaba: «De aquí adelante no se fabrique ningún convento, ni se comience obra notable del, sin que preceda traza de los artífices de la orden, en que esté delineada la forma que ha de tener. $Y$ esta mandamos, que sin falta se guarde, y no se añada, ni quite cosa alguna della, sin especial licencia del Padre General, y de consentimiento del mismo artífice; (los quales guarden en todo las medidas desta Constitución) los que hicieren o permitieren lo contrario, sean suspendidos de oficio según la gravedad del delito. No se comience a hacer en ninguna parte obra notable, que pase de cien ducados de costa, sin tener primero licencia en escrito del Provincial». Citado en Echeverría Goñi y Fernández Gracia, 1982, pp. 187-188.

20. Muñoz Jiménez, 1989b, pp. 407-431.

21. Echeverría Goñi y Fernández Gracia, 1982, pp. 203-206.

22. Muñoz Jiménez, 1990b.

23. Muñoz Jiménez, 1989c, pp. 65-90. 
imperante de comienzos del XVII, como reflejan el convento de San José de Medina de Rioseco (1606) y el convento de la Encarnación de Lerma (1608)24. Diseños que igualmente ejecutó para otras congregaciones religiosas y una clientela selecta, como el convento de agustinas recoletas de la Real Encarnación de Madrid (16111616) ${ }^{25}$, su obra más insigne, promovido por la reina Margarita de Austria (Imagen 1). También trabajó al servicio del duque de Lerma, Francisco Gómez de Sandoval y Rojas, para el que proyectó la mayor parte del conjunto palaciego ducal de su villa natal, ante el fallecimiento repentino del arquitecto real Francisco de Mora en $1610^{26}$, así como la colegiata y conventos dominicos de Santo Domingo y San Blas en la misma localidad ${ }^{27}$ concluidos para 1617. Obras en las que se advierte una gran sencillez en el trazado, con iglesias de una sola nave y coro alto a los pies y

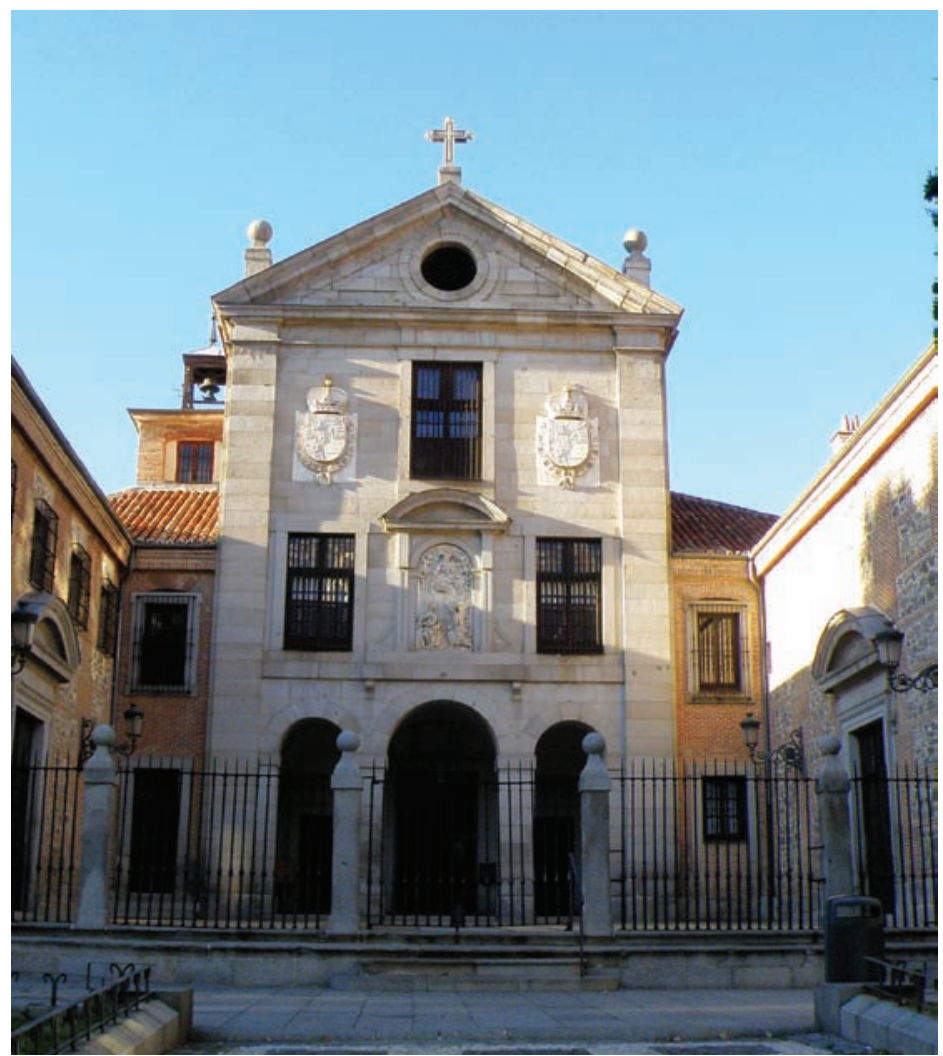

Imagen 1. Fachada del convento de agustinas recoletas de la Real Encarnación de Madrid, por fray Alberto de la Madre de Dios (1611-1616).

25. Bustamante García, 1975, pp. 369-388. Muñoz Jiménez, 1990a, pp. 165-168. Sánchez Hernández, 1997, p. 39.

26. Cervera Vera, 1967, pp. 263-508. Muñoz Jiménez, 1989d, pp. 52-59.

27. Cervera Vera, 1981, pp. 27 y 71. Cervera Vera, 1969a, pp. 31-40. Cervera Vera, 1969b, pp. 37-43. Casillas García, 2008, pp. 139-131. 
fachadas que se resuelven en un rectángulo vertical, divididas en tres cuerpos de altura y rematadas con frontón triangular, respondiendo al modelo de fachada carmelitana, de origen palladiano, generalmente recorridas por pilastras toscanas de orden gigante, con la puerta de entrada, la hornacina con la imagen del titular, los escudos de los promotores y la ventana para el coro.

Un estilo severo y elegante que siguieron practicando los frailes carmelitas a mediados del siglo XVII, como fray Nicolás de la Purificación ${ }^{28}$, mientras que otros plasmaron fachadas más novedosas, como ejemplifica fray Alonso de San José (1600-1654) ${ }^{29}$ en el diseño de la iglesia del convento de Santa Teresa de Ávila (16291636) ${ }^{30}$ (Imagen 2), cuya portada con torres laterales muestra una «sumptuosidad,

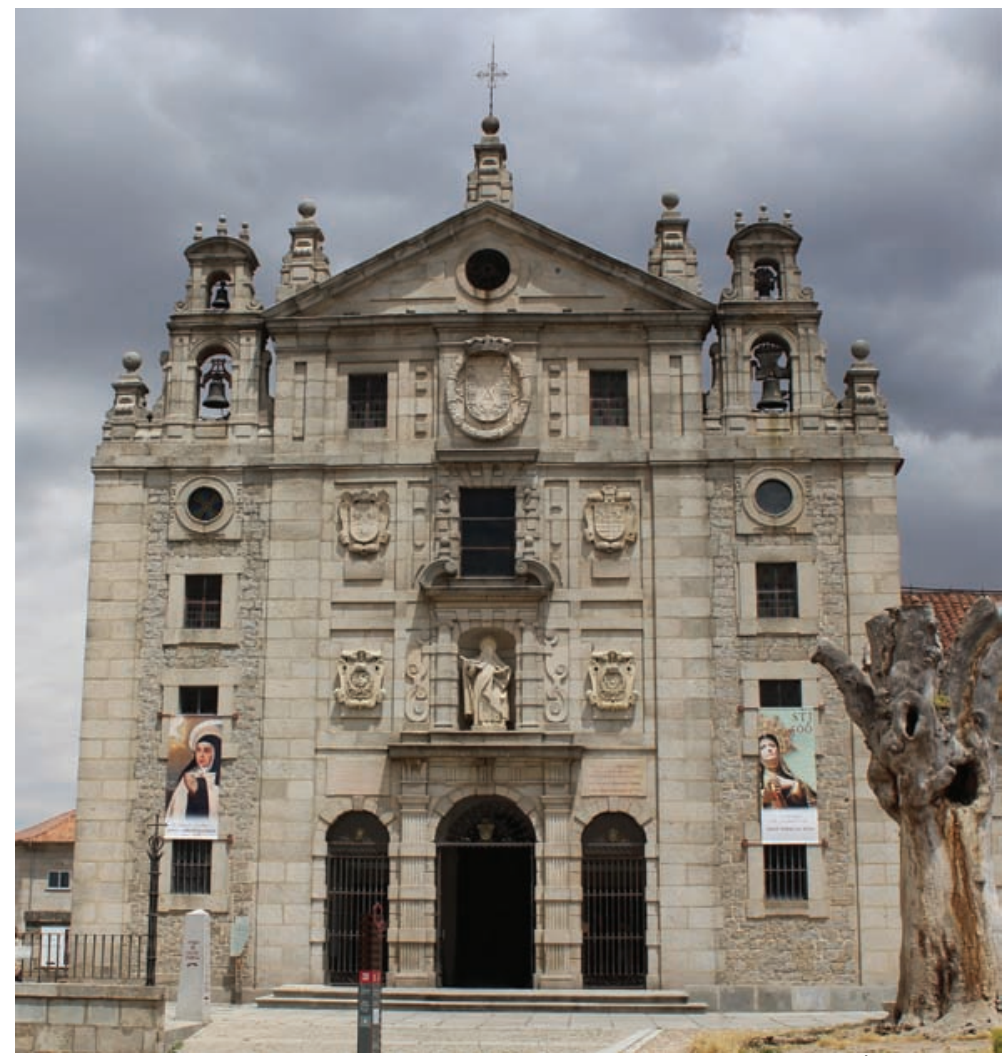

Imagen 2. Fachada de la iglesia del convento de Santa Teresa de Ávila, por fray Alonso de San José (1629-1636).

28. Echeverría Goñi y Fernández Gracia, 1982, pp. 207-208.

29. Su prolífica carrera como tracista de la Orden le llevó a tener una fecunda labor artística durante la primera mitad del XVII a lo largo de Castilla, la Rioja y Navarra, suministrando trazas para importantes parroquias, catedrales o santuarios. Muñoz Jiménez, 1986, pp. 429-434. Echeverría Goñi y Fernández Gracia, 1982, pp. 188-191.

30. Martín González, 1976, pp. 305-324. Arnaiz Gorroño, Cantera Montenegro, San Román y Gutiérrez Robledo, 1986. 
apariencia y ostentación maior de lo que la estrechez y reformación acostumbra» ${ }^{31}$, que en parte obedece al patronato que desde 1631 ostentó el conde duque de Olivares.

Con la llegada del siglo XVII los frailes tracistas del Carmelo Teresiano supieron discernir perfectamente la sencillez arquitectónica del prototipo carmelitano en las construcciones de la Orden, del exuberante barroco tardío visible en aquellos proyectos acometidos fuera del claustro para promotores ajenos, según se advierte en la figura de fray José de la Concepción, activo en la provincia carmelitana de Cataluña ${ }^{32}$, o fray José de San Juan de la Cruz (1714-1794), presente en La Rioja, Navarra y Álava en la segunda mitad de la centuria, al que aludiremos más adelante.

\section{LA CIUDAD CONVENTO. EL CONJUNTO DE LOS DESCALZOS DE PAMPLONA}

El convento de carmelitas descalzos de Santa Ana de Pamplona se erigió dentro de los muros de la ciudad bien entrado el siglo XVII, después de haber vivido los religiosos desde 1587 extramuros en el barrio de la Magdalena, merced a la iniciativa del noble navarro Martín Cruzat ${ }^{33}$. Un traslado que facilitó la labor apostólica de los frailes, aunque surgieron inconvenientes a la hora de edificar el convento, especialmente ante la escasez de suelo urbano y la oposición de otras comunidades religiosas instaladas previamente en la ciudad, principalmente de la parroquia de San Lorenzo en cuyo ámbito jurisdiccional se emplazaron. Una vez obtenida la oportuna licencia de manos del padre general, fray Juan del Espíritu Santo, el 20 de mayo de 1637, se solicitó la presencia del tracista fray Nicolás de la Purificación, quien se desplazó desde el convento carmelitano de Calahorra en el que residía, emitiendo un informe favorable sobre el lugar elegido para la construcción del nuevo convento al final de la calle de Carnicerías Viejas, en el burgo de San Cernin, cuyas trazas le fueron encargadas. Proyecto en el que también participó de alguna manera el tracista fray Alonso de San José, con motivo en 1639 de su nombramiento como prior del complejo pamplonés ${ }^{34}$.

Las dimensiones del edificio conventual exigieron a los frailes adquirir entre 1640 y 1660 la elevada cifra de 71 casas situadas entre la muralla que mira a la Rochapea y las calles Urradinda, Arrias Oranza y Santo Andía, por las que pagaron un alto precio, más de 10.000 ducados, debido a la especulación de los propietarios, inmuebles que fueron comprados poco a poco, según se construía el convento y se recaudaba dinero ${ }^{35}$. Las obras se iniciaron, tras el establecimiento de los carmelitas en el emplazamiento definitivo, en octubre de 1640, y los primeros trabajos de derribo y acondicionamiento del suelo por el claustro y sus dependencias, en los que trabajaron los maestros Juan de Urquía y José de Lagurrea.

31. Muñoz Jiménez, 1985, pp. 15-95.

32. Narváez i Cases, 2002.

33. Ostiz Urriza, 1981, pp. 721-786; Fernández Gracia y Echeverría Goñi, 1981, pp. 787-818; Fernández Gracia y Echeverría Goñi, 1982, pp. 17-19; Maquirriain, 1994, pp. 13-33.

34. Muñoz Jiménez, 1990a, pp. 225-228 y 249-251.

35. Maquirriain, 1994, pp. 53-69. 
La progresiva ocupación de los solares circundantes obligó a modificar el trazado urbano existente, cerrando en 1647 la calle de Urradinda, sobre la que se construyó la nave de la epístola de la iglesia, tal y como refleja un plano original del siglo XVII del Archivo de Carmelitas Descalzos de Pamplona (Imagen 3) ${ }^{36}$. El

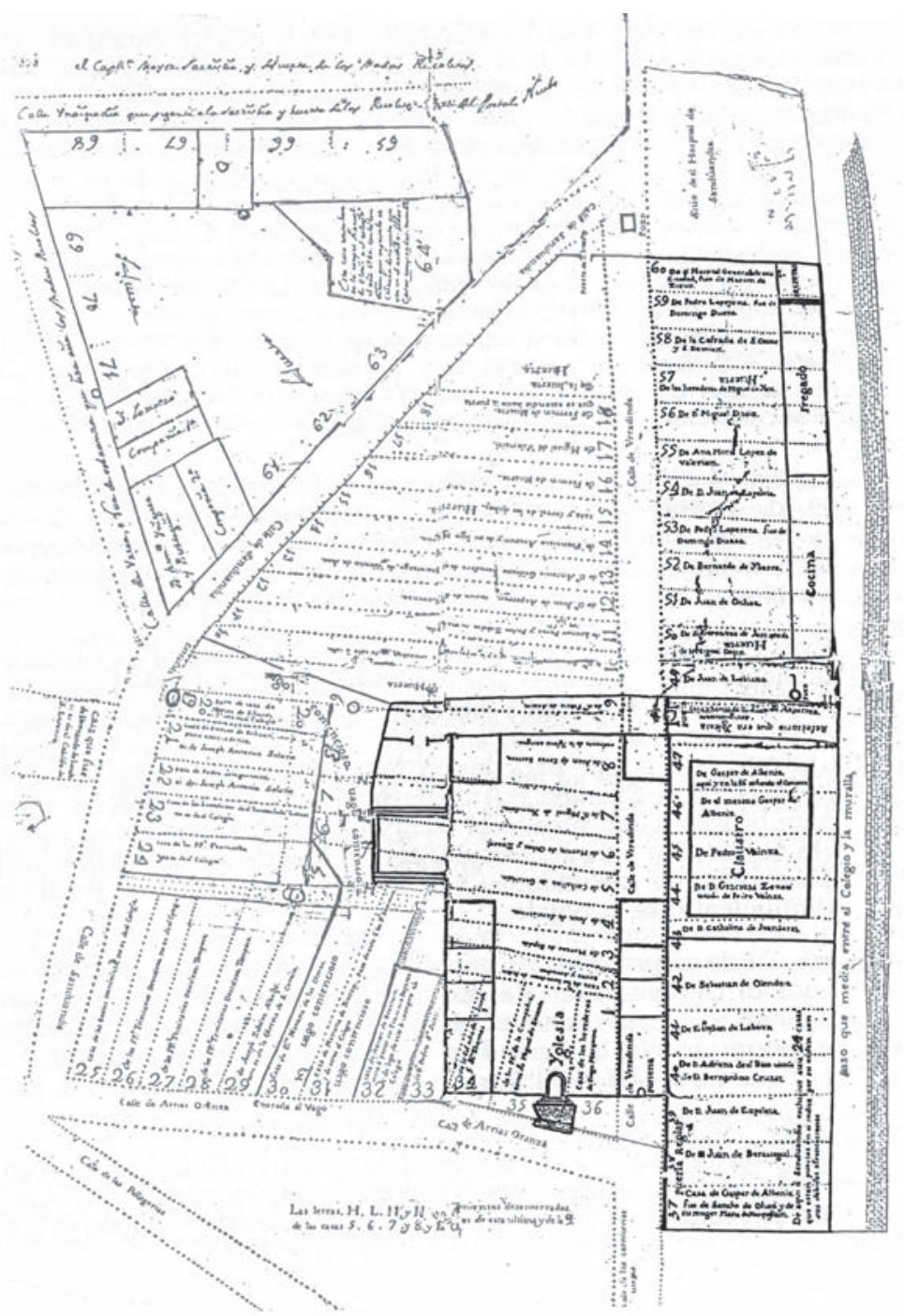

Imagen 3. Plano del sector urbano de Pamplona sobre el que se construyó el convento de carmelitas descalzos de Santa Ana, en el que se resaltan la iglesia, el complejo conventual y sus dependencias.

36. Maquirriain, 1994, p. 54. Agradecemos al Padre Ildefonso Moriones su absoluta disponibilidad para acceder al archivo y convento de Santa Ana de Pamplona, así como su interés por aclarar todas las cuestiones que le hemos planteado referentes al Carmelo Teresiano. 
anónimo dibujo reproduce el sector urbano de la ciudad sobre el que se asentó el complejo conventual de Santa Ana a partir de 1640, formado por el claustro, el colegio y las dependencias de servicio, como el refectorio y la cocina, además de la iglesia definitiva erigida entre 1662 y 1669, con la cabecera al oeste y el claustro adosado al lado norte de la nave. Templo cuya sobria fachada pétrea de los pies acometió entre 1667 y 1672 el cantero Pedro de Azpíroz siguiendo el modelo del convento de Lazcano (Guipúzcoa), de acuerdo al esquema habitual carmelitano, formado por un paramento central rectangular de disposición vertical coronado por frontón triangular, al que se añaden otros menores, unidos por aletones, quedando la portada presidida por la imagen de la titular Santa Ana (Imagen 4), fachada sobre cuyas mediciones emitió su parecer en 1673 fray Juan de San José desde Alba de Tormes.

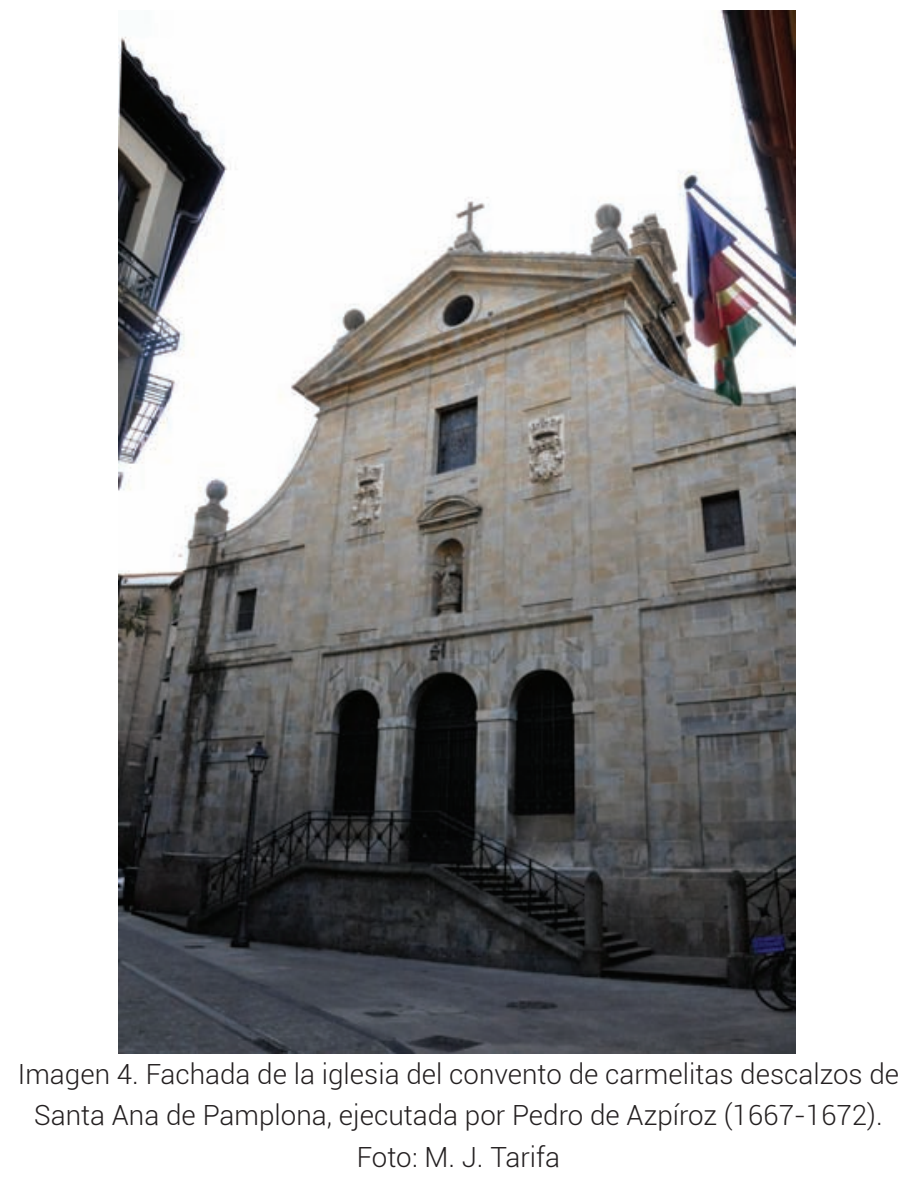

Una iglesia de planta de cruz latina, de tres naves con capillas laterales entre los contrafuertes, coro alto a los pies y tribunas en el espacio de la cabecera recta. Un templo que al interior destaca por su sobriedad decorativa, con la utilización de pilastras de orden dórico-toscano sobre las que montan una cornisa moldurada 
de sencillas líneas que corre a su altura y a lo largo de todo el perímetro el edificio, dando paso a las cubiertas de los cinco tramos de la nave, de bóveda de medio cañón con lunetos que revisten su intradós con una estereotipada composición de dibujos geométricos en yeso, en la línea de los repertorios ornamentales para bóvedas recogidos por fray Lorenzo de San Nicolás en su tratado Arte y Uso de Arquitectura, al igual que la media naranja del crucero que igualmente decora su trasdós con yeserías de tipo geométrico ${ }^{37}$.

\section{LA EXCEPCIONALIDAD DE UNOS PLANOS ORIGINALES CON LA ESTRUCTURACIÓN CONVENTUAL DE LOS ESPACIOS: LOS DISEÑOS ARQUITECTÓNICOS DEL COMPLEJO DE LESACA POR FRAY JOSÉ DE SAN JUAN DE LA CRUZ (1767)}

Dentro del convento hay un organigrama de espacios adecuado a la vida activa y contemplativa, con ámbitos compartidos, como la iglesia o el refectorio, y otros dedicados al retiro, a la oración y al silencio, como las celdas; desde aquellos que sirven para la comunicación con el exterior, a través de los locutorios y la puerta reglar, a los que posibilitan el recogimiento de la vida de clausura con la disposición de altas tapias y espesas rejas.

Un claro ejemplo de cómo se organizan los distintos espacios que conforman el complejo conventual carmelitano descalzo se puede apreciar a través de los dibujos arquitectónicos del siglo XVIII trazados para la ejecución del convento de religiosas de Lesaca (Navarra), erigido bajo la advocación de Nuestra Señora de los Dolores, gracias a la generosidad de su fundador, el indiano Ignacio de Arriola ${ }^{38}$. Plantas y alzados que fueron realizados en 1767 por fray José de San Juan de la Cruz (1714-1794), un religioso excepcional en el campo de las artes que aunaba las especialidades de tracista, ingeniero, arquitecto y dorador ${ }^{39}$.

Un edificio que ante la amenaza de una industria instalada en sus proximidades fue demolido en 1992, quedando únicamente en pie la iglesia ${ }^{40}$, presidida por la fachada de los pies de sillar gris, espacio que ha sido habilitado como casa de cultura. Circunstancia que pone en alza más aún, si cabe, el valor de estas trazas como documentos histórico-artísticos que nos permiten reconstruir la configuración originaria del convento.

El tracista descalzo, procedente del convento de Logroño, se personó en la villa navarra a comienzos de abril de 1767, acompañado de una primera planta y medidas del edificio conventual, encaminada a facilitar la elección del terreno. Tras ello, elaboró los planos que responden al esquema típico de convento carmelitano y que son sumamente clarificadores en lo que a la distribución y funcionalidad de los es-

37. García Gainza, Orbe Sivatte, Domeño Martínez de Morentin y Azanza López, 1997, pp. 269-294; Azanza López, 1998a, pp. 291-296.

38. García Gainza, 1973, pp. 333-344.

39. Echeverría Goñi, y Fernández Gracia, 1982, pp. 195-199. El lego carmelita intervino en las parroquias navarras de Viana, catedral de Calahorra, basílica de San Gregorio Ostiense para la que elaboró las trazas y la sacristía de la catedral de Burgos, entre otros proyectos constructivos.

40. García Gainza, 17 de mayo de 1992, p. 56. 
pacios respecta, identificados con leyendas y elaborados de acuerdo a la escala de pies de Castilla, dibujos que firmó y fechó en Lesaca el 28 de noviembre de $1767^{41}$ y de acuerdo a los que se construyó el convento entre octubre de 1767 y octubre de $1770^{42}$.

El plano de la primera planta (Imagen 5), en el que el complejo conventual adopta una disposición rectangular, muestra en el extremo derecho una iglesia de cruz latina, a la que se adosan por el exterior de la cabecera y crucero del lateral de la Epístola una serie de dependencias, como la sacristía de las monjas y la sacristía de los eclesiásticos, relacionadas ambas por el torno, disponiéndose por el exterior de la nave la vivienda del capellán, sin conexión con el templo. A los pies de la iglesia se dispone un pórtico y la puerta reglar, únicos accesos desde el exterior al espacio sagrado y al interior del convento, quedando también fuera del complejo el dormitorio destinado a la demandadera. Así se establece una clara separación entre el mundo exterior y la rígida clausura que introduce Santa Teresa de Jesús en los conventos del Carmelo Teresiano, impidiendo no sólo la salida de las religiosas

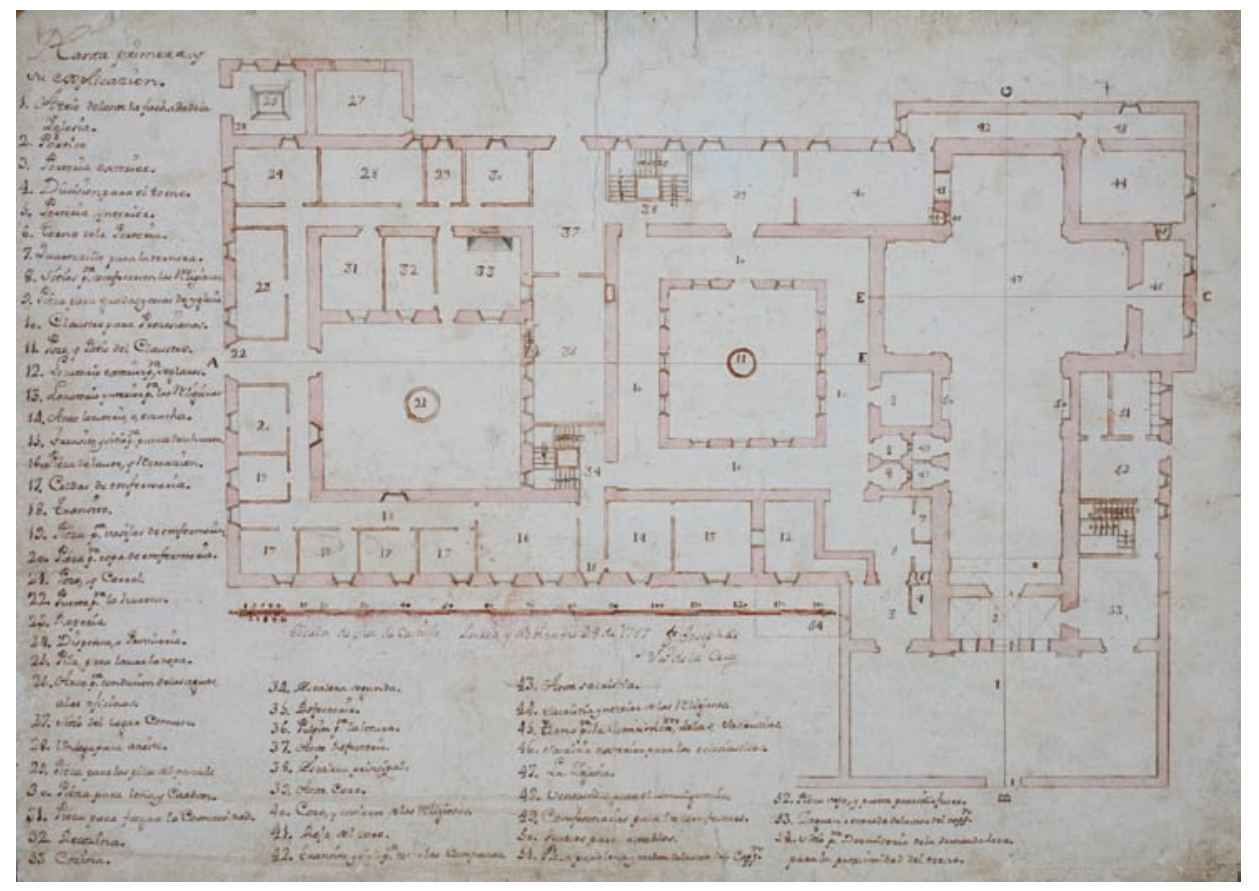

Imagen 5. Planta original del primer piso del convento de carmelitas descalzas de Lesaca, por fray José de San Juan de la Cruz (1767). Archivo de las Carmelitas de Lizaso.

41. Fondos procedentes del Archivo Conventual de Lesaca. Archivo de las Carmelitas de Lizaso. La comunidad de Lizaso se ha trasladado a la localidad riojana de Calahorra.

42. Las obras fueron llevadas a cabo por Manuel de Olóriz y Miguel Antonio de Olasagarre, maestros canteros vecinos de Pamplona y Juan José de Amestoy y Pedro Martín de Tapia, maestros de obras vecinos de Lesaca. García Gainza, Orbe Sivatte, Domeño Martínez de Morentin y Azanza López, 1996, pp. 299-303; Azanza López, 1998a, pp. 334-339. 
del edificio, sino también la entrada de personas ajenas al mismo, tal y como recogen sus constituciones ${ }^{43}$.

Adosada a la iglesia por el lateral izquierdo se organizan el resto de las dependencias conventuales, agrupadas en torno a dos espacios principales, el claustro, con función procesional en el piso inferior, y un patio de servicios. Las dependencias articuladas en torno al claustro, sirven unas, las contiguas a la fachada, de relación con el exterior ya que están destinadas a locutorio y antelocutorio, mientras que las otras permiten la comunicación con el templo, como los confesionarios que dan a la nave, o el coro bajo dispuesto a un lado del altar mayor y cerrado por una reja, con una pequeña ventana para comulgar. Por su parte, las dependencias que se articulan alrededor del patio, desde el que también se accede a la huerta, responden a las estancias por las que transcurre la vida material de las religiosas, como la enfermería y sus celdas, la cocina, el refectorio con el púlpito para la lectura, la ropería y otras dependencias para almacenar alimentos.

La segunda planta dibujada por san Juan de la Cruz (Imagen 6) se corresponde con el cuerpo alto del edificio, mostrando los mismos espacios descritos en el

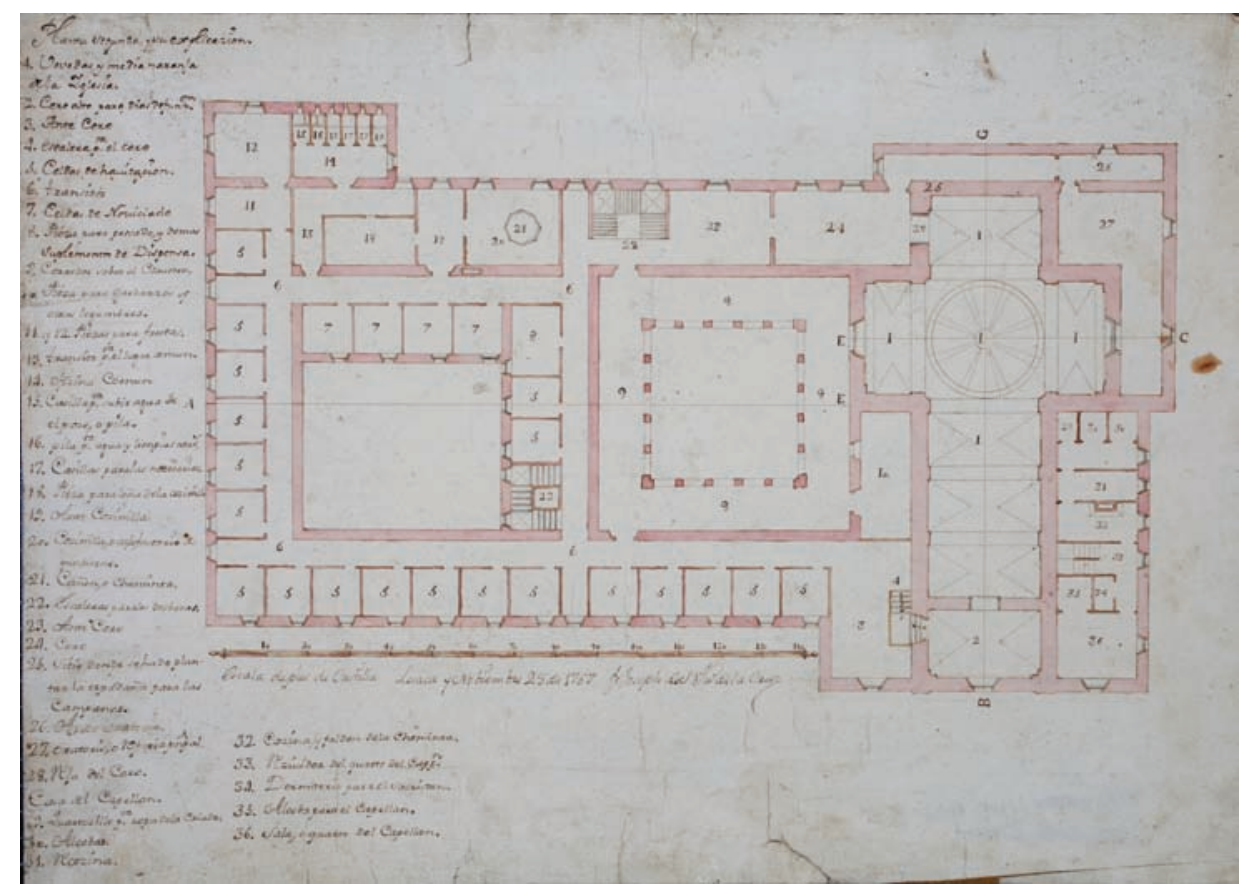

Imagen 6. Planta original del segundo piso del convento de carmelitas descalzas de Lesaca, por fray José de San Juan de la Cruz (1767). Archivo de las Carmelitas de Lizaso.

43. «que ninguna religiosa con ningun motivo salga de la clausura, aunque sea a la Iglesia con pretexto de componer los altares, ni a cerrar la puerta exterior de la portería: pues para dichos ministerios tendrán un sacristán que sea de confianza, y una mandadera virtuosa y honesta, que habiten fuera del atrio y portería de convento; quienes cerrarán las puertas de esta y de la Iglesia, que tendrán sus competentes cerraduras» (Regla primitiva..., 1787, fol. 43). 
dibujo anterior, como la iglesia, cubierta con bóvedas de lunetos y una cúpula de media naranja en el tramo central del crucero, y al exterior la casa del capellán y sacristán. En el claustro y patio se señala un corredor que conduce a las celdas de las monjas y novicias y otras habitaciones de servicio, como las «nezesarias» y el calefactorio. Del análisis de ambas plantas se deduce que el convento ha sido proyectado en función de las necesidades de la vida conventual y la práctica de la regla, siguiendo las recomendaciones de Santa Teresa de Jesús de atender a lo necesario sin caer en lo superfluo.

Otro de los dibujos realizado por el fraile tracista muestra la sección longitudinal del convento (Imagen 7), desde la puerta de la huerta, pasando por el patio, claustro e iglesia, con los dos niveles de altura, que permiten identificar las estancias señaladas anteriormente en las plantas, como el refectorio con el púlpito o el claustro procesional cerrado en el piso inferior, o el sobreclaustro con una galería abierta al exterior, además de las celdas para las monjas y las novicias que ocupan la mayor parte del segundo piso. A continuación se delinean los distintos espacios del templo a la altura del crucero, cubierto por media naranja en el tramo central, enmascarado por un cimborrio octogonal al exterior, y bóvedas de lunetos en los brazos, dibujando también la capilla mayor, además de las pilastras dóricas que articulan la única nave caracterizada por su sobriedad estructural. Para clarificar más el diseño, emplea tintas de distintos colores, como la rosácea para marcar el grosor de algunos de los muros, o la de tonalidad amarilla para destacar los entramados de madera.

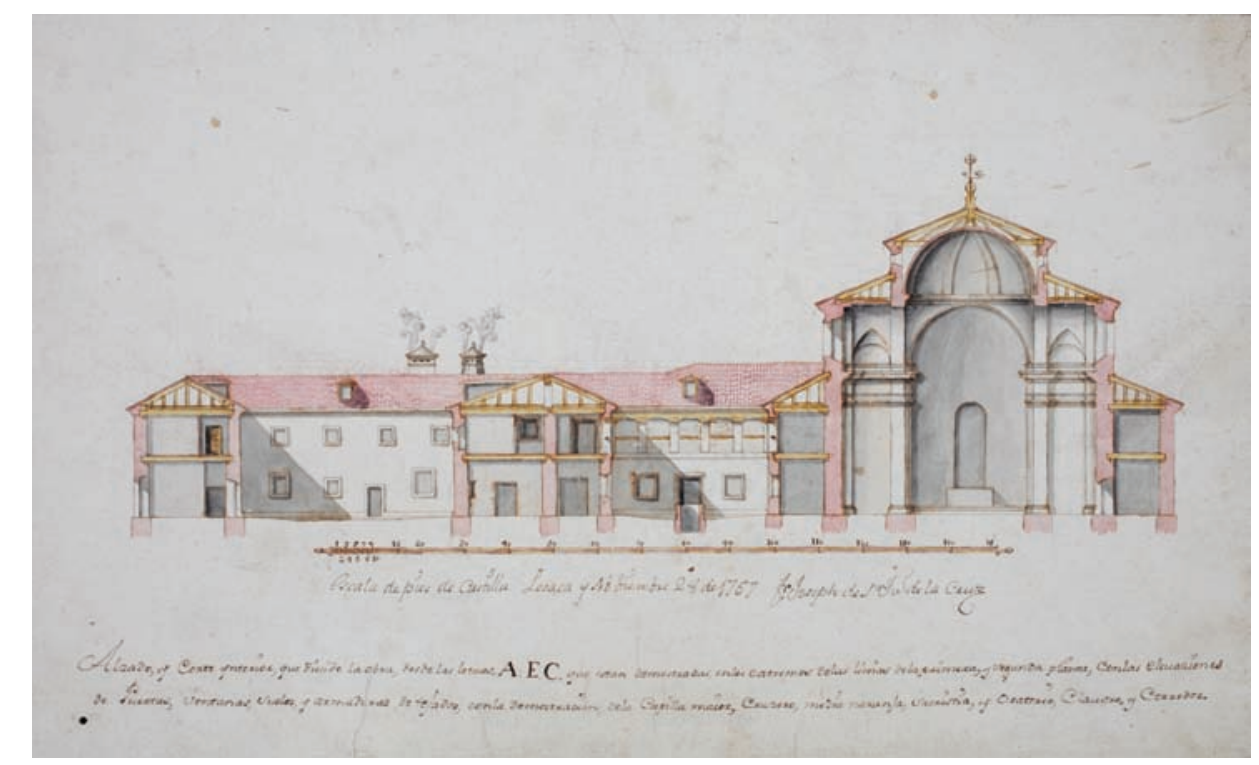

Imagen 7. Dibujo original con la sección longitudinal del convento de carmelitas descalzas de Lesaca, por Fray José de San Juan de la Cruz (1767). Archivo de las Carmelitas de Lizaso. 
José de San Juan de la Cruz también trazó el alzado y corte interior de la iglesia (Imagen 8), en la línea de los dibujos recogidos por fray Lorenzo de San Nicolás en su tratado Arte y Uso de Arquitectura, utilizando diferentes tintas de colores como en el caso anterior, cuyo espacio arquitectónico se ajusta a las características propias de una iglesia conventual de carmelitas descalzas. Un templo precedido por un atrio, al que sucede el nártex sotocoro que sirve de ingreso al interior, sobre el que se coloca en alzado el coro alto, que enlaza con la única nave dividida en tres tramos, crucero y cabecera recta. Articulan los muros perimetrales pilastras de capitel dórico que soportan un entablamento, por encima del cual se elevan las bóvedas de lunetos y media naranja que voltea el tramo central del crucero, cubriéndose todo ello con una armadura de madera. También se dibuja en el muro de la nave el hueco para albergar el retablo y los nichos destinados a confesionarios, y en el espacio de la cabecera los vanos de comunicación con el coro y la pequeña ventana para comulgar.

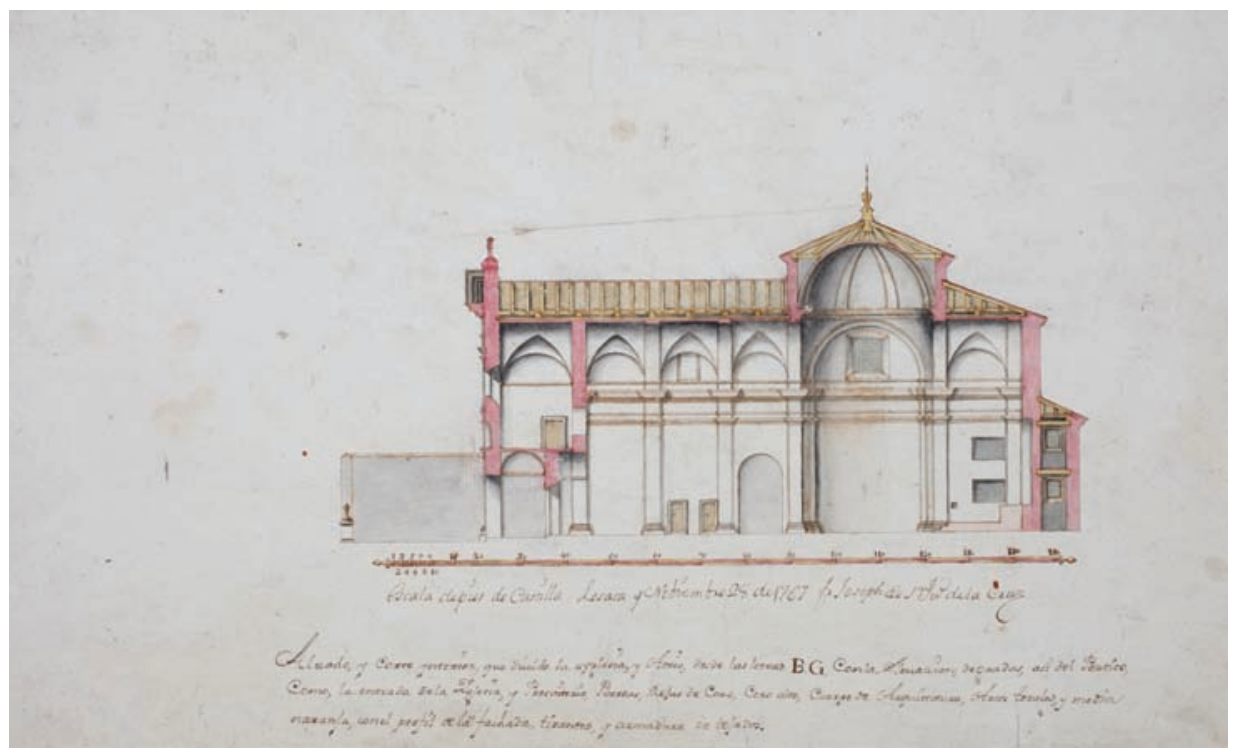

Imagen 8. Dibujo original con la sección longitudinal de la iglesia del convento de carmelitas descalzas de Lesaca, por Fray José de San Juan de la Cruz (1767).

Archivo de las Carmelitas de Lizaso.

Otro de los dibujos de san Juan de la Cruz es un alzado del exterior del convento (Imagen 9), con la fachada longitudinal que da a los pies de la iglesia, recorrida por dos líneas de ventanas que se corresponden a los dos pisos de altura del complejo, vanos de distinto tamaño y distribuidos sin ritmo espacial alguno. Edificio al que se une la sobria y pétrea portada de la iglesia precedida del atrio, que siguiendo el esquema habitual en la Orden se compone de un paramento central rectangular de disposición vertical enmarcado por dos pilastras lisas sobre las que corre un friso de triglifos y metopas, rematado por frontón triangular partido en el que se inscribe una cruz, quedando este espacio flanqueado por dos alas laterales de menor altura, 


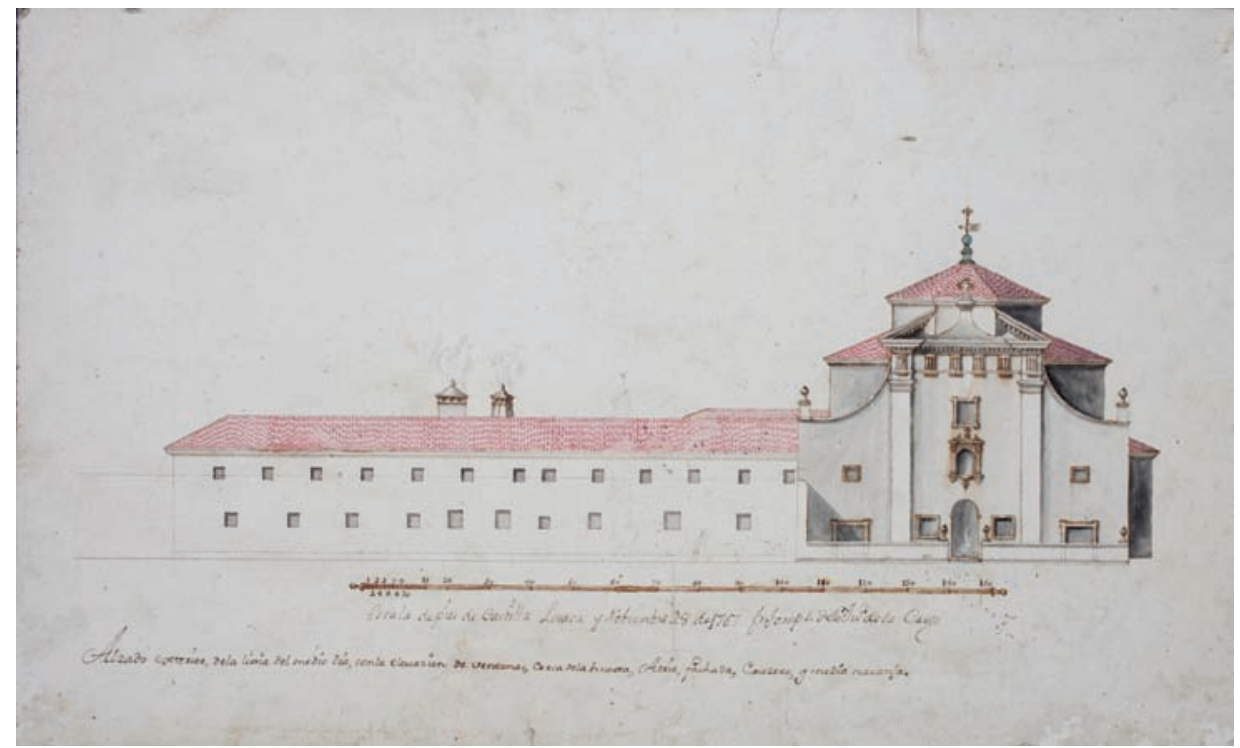

Imagen 9. Dibujo original del alzado exterior del convento de carmelitas descalzas de Lesaca, por Fray José de San Juan de la Cruz (1767). Archivo de las Carmelitas de Lizaso.

con puertas y ventanas, que se unen mediante aletones curvos. En el plano central se aprecia la triple división en altura, con una puerta de medio punto de ingreso delimitada por dos ventanas cuadradas, encima una hornacina entre pilastras coronada por frontón partido, y sobre ella una ventana rectangular moldurada con orejetas. Un diseño de fachada que fue respectada en su ejecución, introduciendo leves cambios, como la colocación de los escudos de los patronos a ambos lados de la hornacina, en el interior de la que se dispuso la titular del convento, Nuestra Señora de los Dolores con el Niño, así como la eliminación del friso de triglifos, sustituido por uno liso, y la parte central del frontón que remata en una esbelta espadaña en vez de con la cruz señalada en el dibujo (Imagen 10). El esquema general evidencia un conocimiento por parte del tracista carmelita de los modelos para fachadas y frontispicios propuestos por fray Lorenzo de San Nicolás en su Arte y Uso de la Arquitectura ${ }^{44}$, ya que la fachada del convento de Lesaca se asemeja bastante a uno de ellos, aunque reduciendo los elementos ornamentales.

En definitiva, el convento en su disposición arquitectónica se muestra subordinado al espíritu, regla y finalidad de la Orden a la que pertenece, por lo que los principios inspiradores de la arquitectura conventual no se basaron principalmente en normas estéticas, sino en valores intangibles e inmateriales. Las distintas dependencias que lo integran responden a un plan preconcebido diseñado por un fraile tracista que pretende ofrecer la mayor funcionalidad, por lo que el esquema planimétrico utilizado por los carmelitas descalzos apenas sufrió variaciones en las distintas fundaciones que llevaron a cabo en el territorio peninsular a lo largo de los 


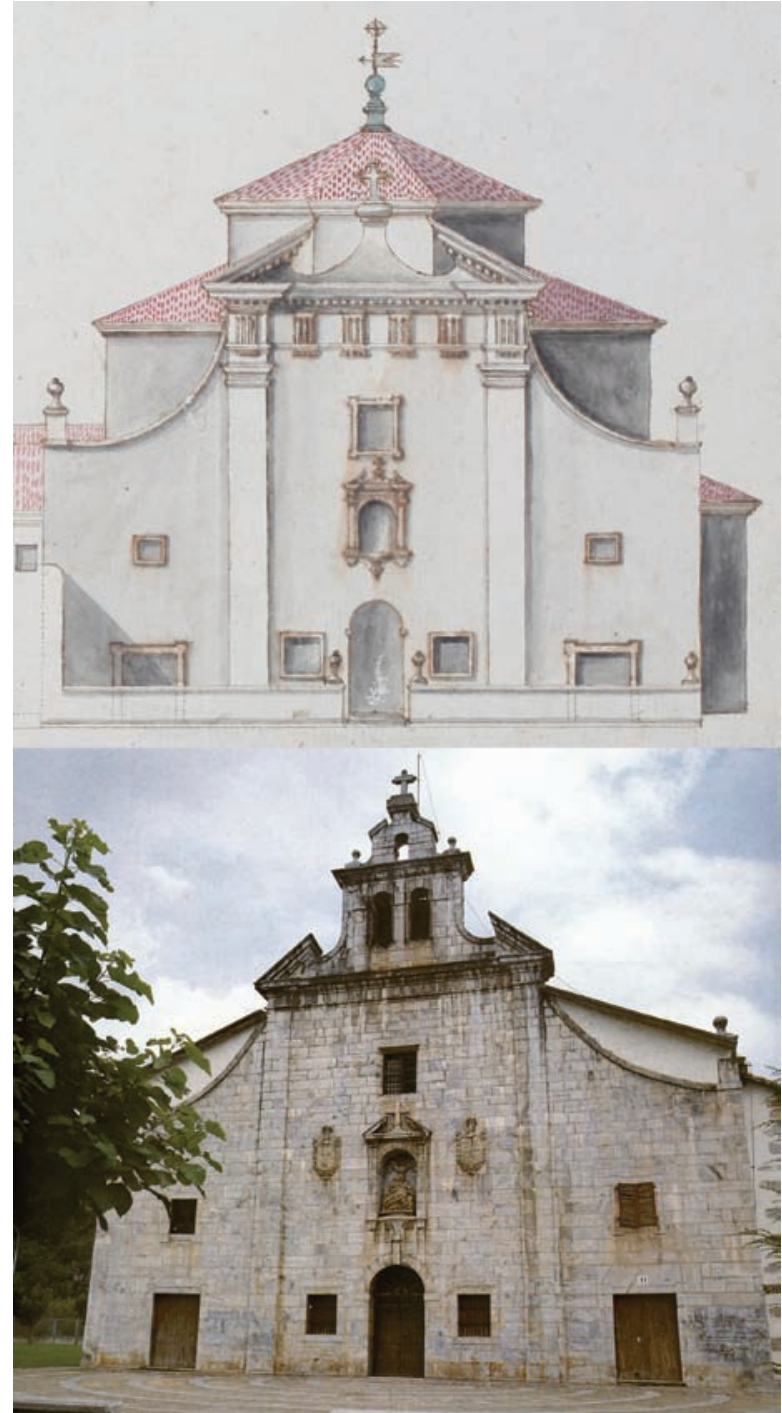

Imagen 10. Detalle del dibujo original de la fachada de la iglesia del convento de carmelitas descalzas de Lesaca, por Fray José de San Juan de la Cruz (1767) y fachada de la misma iglesia en la actualidad.

siglos XVI y XVIII. Complejos conventuales en los que a través de la configuración arquitectónica y espacial se hace visible y palpable el nuevo estilo de vida teresiano, definido por la coherencia de lo interior con lo exterior, el equilibrio entre la soledad y la vida en comunidad, entre el silencio y la comunicación, en definitiva, entre la clausura y la presencia en la ciudad. 


\section{BIBLIOGRAFÍA}

Arnaiz Gorroño, María José, Jesús Cantera Montenegro, Carlos Clemente San Román y José Luis Gutiérrez Robledo, La Iglesia y Convento de la Santa en Ávila, Ávila, Institución «Gran Duque de Alba» de la Excma. Diputación Provincial de Ávila, 1986.

Atienza López, Ángela, Tiempos de conventos. Una historia social de las fundaciones en la España moderna, Madrid, Marcial Pons, 2008.

Azanza López, José Javier, Arquitectura religiosa del Barroco en Navarra, Pamplona, Gobierno de Navarra, 1998a.

Azanza López, José Javier, «La "iglesia en la ciudad": arte, economía y espiritualidad en Navarra a la luz de las fundaciones conventuales barrocas», Príncipe de Viana, 215, 1998b, pp. 579-613.

Bustamante García, Agustín, «Los artífices del Real Convento de la Encarnación de Madrid», Boletín del Seminario de Arte y Arqueología, 40-41, 1975, pp. 369388.

Cámara Muñoz, Alicia, Arquitectura y sociedad en el Siglo de Oro. Idea, traza y edificio, Madrid, El Arquero, 1990.

Casillas García, José Antonio, El monasterio de San Blas de la villa de Lerma: una historia inmóvil, Salamanca, San Esteban, 2008.

Cervera Vera, Luis, El conjunto palacial de la villa de Lerma, Valencia, Castalia, 1967.

Cervera Vera, Luis, El convento de Santo Domingo en la villa de Lerma, Madrid, Castalia, 1969a.

Cervera Vera, Luis, El monasterio de San Blas en la villa de Lerma, Valencia, Castalia, 1969b.

Cervera Vera, Luis, El monasterio de la Madre de Dios en la villa de Lerma, Valencia, Castalia, 1973.

Cervera Vera, Luis, La Iglesia Colegial de San Pedro de Lerma, Burgos, Caja de Ahorros Municipal, 1981.

Echeverría Goñi, Pedro y Ricardo Fernández Gracia, «Aportación de los Carmelitas Descalzos a la historia del arte navarro: Tracistas y arquitectos de la Orden», en Santa Teresa en Navarra. IV Centenario de su muerte, Pamplona, Grafinasa, 1982, pp. 183-230.

Escribano Hernández, Julio, «Las fundaciones de Santa Teresa», Cuadernos de Investigación Histórica, 11, 1987, pp. 201-230.

San José, Félix Mateo de, «Canon arquitectónico en la legislación carmelitana», Monte Carmelo, 52, 1948, pp. 117-122. 
Fernández de Mendiola, Domingo Ángel, El Carmelo Teresiano en la historia: una nueva forma de vida contemplativa y apostólica. 1, El Carmelo Teresiano en vida de la Madre fundadora, Teresa de Jesús (1515-1582), Roma, Teresianum, 2008.

Fernández Gracia, Ricardo y Pedro Luis Echeverría Goñi, «El convento e iglesia de los Carmelitas Descalzos de Pamplona. Arquitectura», Príncipe de Viana, 164, 1981, pp. 787-818.

Fernández Gracia, Ricardo y Pedro Echeverría Goñi, «Fundaciones del Carmen Descalzo en Navarra», en Santa Teresa en Navarra. IV Centenario de su muerte, Pamplona, Grafinasa, 1982, pp. 13-25.

García Gainza, María Concepción, «El convento de Carmelitas Descalzas de Lesaca», Boletín del Seminario de Estudios de Arte y Arqueología, 39, 1973, pp. 333-344.

García Gainza, María Concepción, «Adiós al convento de carmelitas descalzas de Lesaca», Diario de Navarra, 17 de mayo de 1992, p. 56.

García Gainza, María Concepción, Mercedes Orbe Sivatte, Asunción Domeño Martínez de Morentin y José Javier Azanza López, Catálogo Monumental de Navarra, $\vee * *$, Merindad de Pamplona, Pamplona, Institución Príncipe de Viana, 1996.

García Gainza, María Concepción, Mercedes Orbe Sivatte, Asunción Domeño Martínez de Morentin y José Javier Azanza López, Catálogo Monumental de Navarra, $\vee * * *$, Merindad de Pamplona, Pamplona, Institución Príncipe de Viana, 1997.

Jedin, Hubert, Manual de Historia de la Iglesia, vol. V, Barcelona, Herder, 1972.

López de Ayala, Ignacio, El Sacrosanto y Ecuménico Concilio de Trento, Paris, Rosa y Bouret, 1857.

Maquirriain, José María, Historia de los conventos de carmelitas descalzos en Pamplona, Pamplona, Gráficas Lizarra, 1994.

Martín González, Juan José, «El convento de Santa Teresa de Ávila y la arquitectura carmelitana», Boletín del Seminario de Estudios de Arte y Arqueología, 42, 1976, pp. 305-324.

Muñoz Jiménez, José Miguel, «Nueva documentación sobre la polémica del convento de Santa Teresa de Ávila (1652-1665): la arquitectura carmelitana en la disyuntiva Manierismo versus Barroco», Monte Carmelo, 93, 1985, pp. 15-95.

Muñoz Jiménez, José Miguel, «El Padre Fray Alonso de San José (1600-1654), arquitecto carmelita», Boletín del Seminario de Estudios de Arte y Arqueología, 52, 1986, pp. 429-434.

Muñoz Jiménez, José Miguel, «La arquitectura de Santa Teresa», Monte Carmelo, 97, 1989a, pp. 127-157. 
Muñoz Jiménez, José Miguel, «La arquitectura en los Desiertos Carmelitanos», Monte Carmelo, 97, 1989b, pp. 407-431.

Muñoz Jiménez, José Miguel, «Sobre la formación y significación del arquitecto montañés fray Alberto de la Madre de Dios (1575-1635)», Altamira: Revista del Centro de Estudios Montañeses, 48, 1989c, pp. 65-90.

Muñoz Jiménez, José Miguel, «Fray Alberto de la Madre de Dios y la arquitectura cortesana: urbanismo en la villa de Lerma», Goya, 211-212, 1989d, pp. 52-59.

Muñoz Jiménez, José Miguel, La arquitectura carmelitana (1562-1800): arquitectura de los Carmelitas Descalzos en España, México y Portugal durante los siglos XVI a XVIII, Ávila, Institución Gran Duque de Alba, 1990a.

Muñoz Jiménez, José Miguel, Fray Alberto de la Madre de dios, arquitecto (15751635), Santander, Tantin, 1990b.

Muñoz Jiménez, José Miguel, "Diccionario de artífices del Carmelo teresiano», Monte Carmelo, 100, 1992, pp. 49-78.

Muñoz Jiménez, José Miguel, «Addenda al diccionario de artífices del Carmelo Descalzo. Arquitectos, Maestros de obras y Ensambladores», Monte Carmelo, 109, 2001, pp. 479-489.

Muñoz Jiménez, José Miguel, «El estilo carmelitano de arquitectura: las vías de formación de los artífices en la descalcez española», Monte Carmelo, 122, 2014, pp. 341-361.

Narváez i Cases, Carme, El tracista fra Josep de la Concepció i l'arquitectura carmelitana a Catalunya, tesis doctoral Universitat Autònoma de Barcelona, 2002, <http://www.tdx.cat/handle/10803/5187> [30/07/2016] .

Narváez i Cases, Carme, «"Todo tosco y sin labrar": el model conventual de santa Teresa i el seu reflex en la normativa arquitectònica de l'orde carmelità desca|ç», Scripta: revista internacional de literatura i cultura medieval i moderna, 6, 2015, pp. 176-189.

Ostiz Urriza, José Miguel, «Fundación de Padres Carmelitas Descalzos en Pamplona y los cien años siguientes (1587-1687)», Príncipe de Viana, 164, 1981, pp. 721-786.

Pérez, Joseph, Teresa de Ávila y las España de su tiempo, Madrid, Algaba, 2007.

Regla Primitiva y Constituciones de la Orden de la Gloriosisima Virgen María del Monte Carmelo, confirmadas por N. SS. P. Pío Papa IV, en 12 de mayo de 1786, Madrid, Imprenta de Joseph Doblado, 1787.

San Nicolás, fray Lorenzo de, Arte y uso de arquitectura, Zaragoza, Colegio Oficial de Arquitectos de Aragón, 1989.

Sánchez Hernández, María Leticia, Patronato regio y órdenes religiosas femeninas en el Madrid de los Austrias: Descalzas Reales, Encarnación y Santa Isabel, Madrid, Fundación Universitaria Española, 1997. 
Teresa de Jesús, Obras completas, (intr. Efren de la Madre de Dios y Otger Steggink), Madrid, Editorial Católica, 1962.

Teresa de Jesús, Libro de las Fundaciones, Madrid, Rialp, 2015.

Sebastián, Santiago, «Sentido del Barroco español», en Los siglos del Barroco, Madrid, Akal, 1997, pp. 5-12.

Silverio de Santa Teresa, Historia del Carmen Descalzo en España, Portugal y América, 7. Fundación de nuevos conventos (1588-1600), Burgos, El Monte Carmelo, 1937.

Steggink, Otger, La reforma del Carmelo Español. La visita canónica del General Rubeo y su encuentro con Santa Teresa, Roma, Institutum Carmelitanum, 1965.

Sturm, Saverio, L'architettura dei Carmelitani Scalzi in età barocca. Principii, norme e tipologie in Europa e nel Nuovo Mondo, Roma, Gangemi, 2002. 
